\title{
Comparative systematic review and meta-analysis of the therapeutic effects of coblation tonsillectomy versus electrocautery tonsillectomy
}

\author{
Fu-Guo Cai ${ }^{1 \#}$, Wei Hong ${ }^{1 \#}$, Yu Ye ${ }^{1}$, Ye-Song Liu $^{2}$ \\ ${ }^{1}$ Department of Otorhinolaryngology-Head and Neck Surgery, Shangrao People's Hospital (Affiliated Shangrao Hospital to Nanchang University), \\ Shangrao, China; ${ }^{2}$ Department of Otorhinolaryngology, Yancheng Third People's Hospital (The Affiliated Yancheng Hospital of Southeast \\ University Medical School), Yancheng, China \\ Contributions: (I) Conception and design: FG Cai; (II) Administrative support: YS Liu; (III) Provision of study materials or patients: W Hong; (IV) \\ Collection and assembly of data: Y Ye; (V) Data analysis and interpretation: FG Cai; (VI) Manuscript writing: All authors; (VII) Final approval of \\ manuscript: All authors. \\ "These authors contributed equally to this work. \\ Correspondence to: Ye-Song Liu. Department of Otorhinolaryngology, Yancheng Third People's Hospital (The Affiliated Yancheng Hospital of \\ Southeast University Medical School), 75 Theater Road, Tinghu District, Yancheng 224000, China. Email: lys_19821231@163.com.
}

Background: Surgical removal of the primary lesion is a common treatment for chronic tonsillitis, recurrent tonsillitis, and tonsillar hypertrophy, and is the most widely performed surgery in otorhinolaryngology. With the development and progress of medical science and technology, the methods of tonsillectomy have gradually diversified, and it is of great significance to seek the best tonsillectomy method. This meta-analysis explored the advantages and disadvantages of coblation tonsillectomy (CT) and electrocautery tonsillectomy (ET).

Methods: The keywords "coblation", "radiofrequency ablation", "electrocautery", and "tonsillectomy" were used to search the PubMed, Embase, Cochrane library, Clinicaltrials.gov, and Google Scholar databases, and randomized controlled trials (RCTs) of the 2 procedures since the establishment of the database were included. After screening and bias risk assessment, a meta-analysis was performed using Stata 16.0 software.

Results: A total of 10 articles met the inclusion criteria and entered the final meta-analysis. There were 1,056 participants, including 547 patients who underwent CT and 509 patients who underwent ET. There was no significant difference in the operation time between CT and ET [standard mean difference (SMD) $=0.39,95 \%$ CI: -0.35 to $1.13, Z=1.044, \mathrm{P}=0.296]$. CT resulted in less intraoperative blood loss than ET (SMD $=-2.62,95 \% \mathrm{CI}:-4.83$ to $-0.41, Z=-2.322, \mathrm{P}=0.020)$. The postoperative pain score of $\mathrm{CT}$ was less than ET, but the difference was not statistically significant ( $\mathrm{SMD}=-0.28,95 \% \mathrm{CI}:-0.58$ to $0.01, Z=-1.866, \mathrm{P}=0.062$ ). CT resulted in less time to return to normal diet after surgery than ET, and the difference was statistically significant ( $\mathrm{SMD}=-0.36,95 \% \mathrm{CI}:-0.60$ to $-0.12, Z=-2.918, \mathrm{P}=0.004)$.

Discussion: CT resulted in less intraoperative blood loss and faster postoperative recovery than ET, but there was no significant difference in operation time, postoperative pain, and the incidence rate of postoperative complications between the 2 groups.

Keywords! Coblation tonsillectomy (CT); electrocautery tonsillectomy (ET); tonsillectomy

Submitted Nov 15, 2021. Accepted for publication Jan 07, 2022.

doi: $10.21037 /$ gs-21-832

View this article at: https://dx.doi.org/10.21037/gs-21-832 


\section{Introduction}

Chronic tonsillitis is caused by the repeated attack of acute tonsillitis. The infection of pathogenic bacteria such as Streptococcus and Staphylococcus in tonsils causes the inflammation of palatine tonsils. Chronic tonsillitis, recurrent tonsillitis, and tonsillar hypertrophy are frequentlyoccurring diseases in otorhinolaryngology. If not treated in time, they may cause respiratory, swallowing, and languagerelated dysfunction. Recurrent inflammation may also cause serious complications such as rheumatic heart disease and nephritis (1). There are surgical and non-surgical methods for the treatment of tonsillitis, for patients with recurrent acute inflammation, peritonsillar abscess, excessive hypertrophy of tonsils and ineffective non-surgical treatment, surgical treatment is recommended (2). With the development and progress of medical science and technology, the methods of tonsillectomy have gradually diversified. At present, the most commonly used methods include coblation tonsillectomy (CT), electrocautery tonsillectomy (ET), conventional cold dissection tonsillectomy (CCDT), ultrasonic scalpel tonsillectomy (UST), and thermal welding tonsillectomy (TWT) (3). ET and CT are currently the most promising surgical methods used in clinical practice (4). ET heats tissue when it comes in contact with the body through the high-frequency high-voltage current generated by the active electrode tip, which separates and coagulates the tissue, thereby performing both cutting and hemostasis (5). However, a previous study (6) concluded that the high-frequency electrotome has a deep heat penetration effect, which results in greater direct and indirect damage to the tissue and greater postoperative pain in patients. CT is a technology that has gradually emerged in recent years, which uses the energy of low-temperature plasma RF to remove the tissue at a lower temperature (40-70 degrees), so as to avoid damage to the tissue, thereby reducing postoperative pain and shortening postoperative recovery time (7). A study by Lee $e t$ al. (8) has reported the clinical efficacy and safety of CT and ET by meta-analysis, however, the study did not distinguish between pediatric and adult patients, and the quality of the literature was poor. Therefore, this study included higher quality randomized controlled trials (RCTs) to explore the best current tonsillectomy method, providing a basis for clinical decisionmaking. We present the following article in accordance with the PRISMA reporting checklist (available at https:// gs.amegroups.com/article/view/10.21037/gs-21-832/rc).

\section{Methods}

\section{Criteria for literature inclusion in the study}

\section{Literature type}

The included studies were RCTs limited to the English language. All non-RCTs or controlled clinical trials (CCTs) were excluded.

\section{Participants}

Children or adults diagnosed with chronic tonsillitis, recurrent tonsillitis, or tonsillar hypertrophy causing dyspnea scheduled to undergo surgical tonsillectomy were included. Participants under 18 years of age were classified as pediatric patients and those over 18 years of age were classified as adult patients.

\section{Description of interventions}

This study includes at least 2 groups of patients undergoing tonsillectomy, that is CT and ET. Other patients were also included, namely those undergoing UST, TWT, and CCDT, while patients undergoing other tonsillectomy procedures were not included in the statistics.

\section{Outcome indicators}

(I) Intraoperative indicators: operation time, intraoperative blood loss. (II) Surgical efficacy indicators: postoperative pain score, postoperative time to return to normal diet, postoperative complications. In order to reduce the possible heterogeneity caused by different pain scoring criteria, we only included literature which used the Visual Analog Scale (VAS). Due to the different pain conditions of the patients at different time points after surgery, we only collected the data at 1 day after surgery. Postoperative complications included nausea and vomiting, bleeding, infection, dehydration, and other complications. The included studies were required to contain 1 or more of the above 2 indicators, and should be able to provide data, also the data were reported as mean value and standard deviation for statistics. For studies reporting outcome indicators in statistical figures, we could not collect the data for summary analysis.

\section{Search strategy and literature identification}

Literature was searched using the PubMed, Embase, Cochrane library, Clinicaltrials.gov, and Google Scholar databases from database establishment to September 
2021. The search keywords were as follows: [coblation/ radiofrequency ablation] AND [electrocautery] AND [tonsillectomy].

\section{Literature screening and data extraction}

After literature retrieval, Endnote X9 software was used for unified management. After duplicate studies were excluded by the software, 2 researchers independently completed the screening of the included studies. Irrelevant articles were excluded by reading the title and abstract. After obtaining the original text and data, studies were further screened. If there was a conflict of opinion between the 2 researchers, a $3 \mathrm{rd}$ researcher was consulted to resolve the difference of opinion.

The 2 researchers independently extracted data including:

(I) Basic information of the literature: title, first author, corresponding author, publication time, name of publication, and contact address.

(II) Basic characteristics of the study: total number of samples, number of groups (the number of cases in the experimental group and the control group), number of samples in each group, and surgical methods (specific steps of CT and ET).

(III) Basic characteristics of participants: participant age, gender, BMI, ethnicity, and disease type.

(IV) Surgical data: amount of fentanyl used, amount of Tylenol or Motilium taken, operation time, intraoperative blood loss, and length of stay in the emergency room.

(V) Results: Postoperative pain, time to return to normal diet, time to return to normal activity, readmission rate, postoperative complications, days of postoperative analgesic tablets, and tonsillar healing rate.

If no data was provided in the study but there was a data address link, the data were obtained based on the link. If there was no data at all, the original author was contacted to obtain the data. If the data could not be obtained, the study was excluded.

\section{Literature bias and quality evaluation analysis}

Quality assessment and grading were performed according to the Cochrane Collaboration's Handbook of Systematic Reviewers. For level A, all quality evaluation criteria, namely random sequence generation, allocation concealment, blind method, withdrawal or loss to follow-up, intention analysis, and baseline conditions, were met. For level B, any one or more of the quality evaluation criteria was only partially satisfied (or unclear). For level C, any one or more of the quality evaluation criteria was completely unsatisfied.

\section{Statistical analysis}

\section{Effect size}

Continuous variables (intraoperative blood loss, postoperative pain score, operation time, time to return to normal diet after operation) were assessed using standard mean difference (SMD) and its 95\% CI. P<0.05 indicated that the result was statistically significant.

\section{Heterogeneity analysis}

The analysis was performed using Stata 16.0 and forest plots were used to present the analysis results. The heterogeneity of the studies was analyzed using $\mathrm{I}^{2}$ and $\mathrm{Q}$ calibration, where $\mathrm{I}^{2}>50 \%$ or $\mathrm{P}<0.1$ indicated that the heterogeneity was statistically significant.

\section{Model selection}

If the heterogeneity test determined that the difference between studies was not statistically significant, the fixedeffects model was used to obtain the combined effect value. If heterogeneity among studies was considered, the source of heterogeneity was analyzed first to determine whether a random-effects model should be used.

\section{Publication bias analysis}

Publication bias was represented using funnel plots.

\section{Heterogeneity survey and sensitivity analysis}

Heterogeneity was investigated in groups, and sensitivity analysis was performed using the Influence Analysis tool provided by Stata 16.0.

\section{Results}

\section{Literature search results and screening process}

A total of 1,223 articles were initially found in this search. After screening, a total of 10 studies met the criteria and were included in the final meta-analysis. These 10 studies involved a total of 1,056 participants, including 547 patients who received CT and 509 patients who received ET. Figure 1 shows the literature search results and 


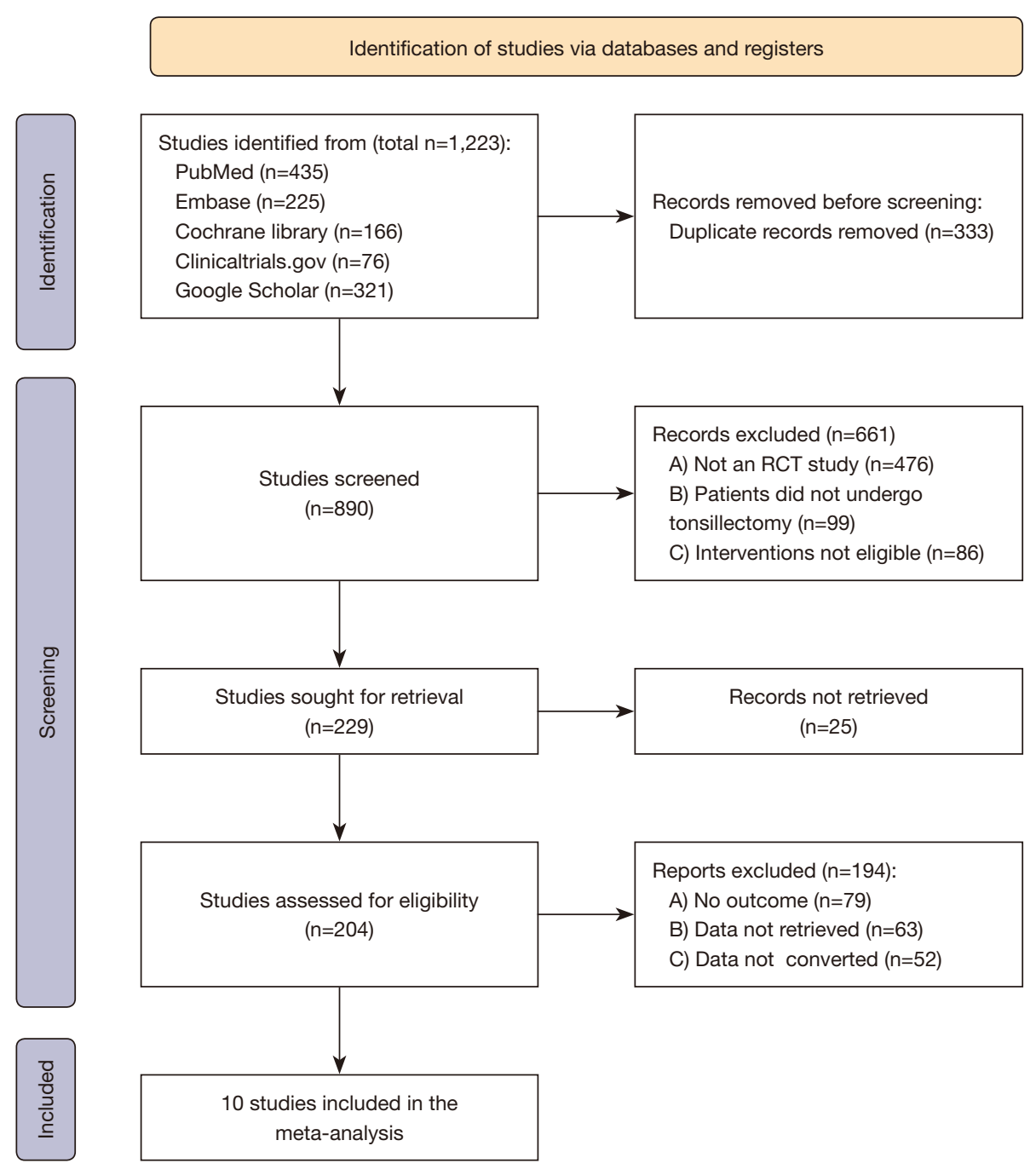

Figure 1 Literature screening flow chart.

screening process.

\section{Basic characteristics of the included literature}

The basic characteristics of the included literature are shown in Table 1.

\section{Bias risk assessment of the included literature}

As shown in Table 2, all studies compared the baseline characteristics between the experimental group and the control group, and the diagnostic criteria and baseline remained consistent. The blind method was described in all studies, allocation concealment was described in studies (9) and (13) only, and the blind method (single blind or double-blind) was described in all studies. A description was provided for patients who were blinded in all studies.

\section{Meta-analysis results}

\section{Operation time}

A total of 7 studies reported the operation times of the 2 operations (both in min). The effect size was expressed by SMD. The homogeneity test results were $I^{2}=95.0 \%$ and $\mathrm{P}<0.0001$. Random effects model analysis showed that there was no significant difference in the operation time between CT and ET (SMD $=0.39,95 \%$ CI: -0.35 to $1.13, \mathrm{Z}=1.044$, 
Table 1 Basic characteristics, patient characteristics, surgical methods, and outcome indicators of the included literature

\begin{tabular}{|c|c|c|c|c|c|c|}
\hline Author & Year & Region & Number of cases $(\mathrm{E} / \mathrm{C})$ & Patient type & Disease type & Outcome indicators \\
\hline Hong et al. (10) & 2013 & Seoul, Korea & $40 / 40$ & Adult & $\mathrm{N} / \mathrm{A}$ & (a) (b) (c) (e) \\
\hline Tan et al. (11) & 2006 & Singapore & $29 / 38$ & Adult & RT & (b) (c) \\
\hline Noordzij et al. (12) & 2006 & Ohio, USA & $40 / 40$ & Adult & $\mathrm{TH}$ & (a) (f) \\
\hline Magdy et al. (14) & 2008 & Egypt & $20 / 20$ & Adult & RT & (a) (f) \\
\hline Chang et al. (15) & 2005 & CA, USA & $52 / 49$ & Child & $\mathrm{TH}$ & (a) (b) (f) \\
\hline Wilson et al. (16) & 2009 & NY, USA & $53 / 53$ & Child & $\mathrm{N} / \mathrm{A}$ & (a) (b) (c) (e) \\
\hline Prussin et al. (17) & 2021 & Utah, USA & $112 / 118$ & Child & $\mathrm{N} / \mathrm{A}$ & (b) (c) (e) \\
\hline
\end{tabular}

Outcomes: (a), operation time; (b), postoperative pain score; (c), postoperative normal diet time; (d), readmission rate; (e), postoperative complications; (f), intraoperative blood loss. NA, not available; E/C, experimental group/control group; CT, chronic tonsillitis; TH, tonsillar/ adenotonsillar hypertrophy; RT, recurrent tonsillitis.

Table 2 Risk of bias assessment and quality grading based on the Cochrane Handbook for the Evaluation of Randomized Interventions

\begin{tabular}{|c|c|c|c|c|c|c|c|}
\hline Study & $\begin{array}{c}\text { Random sequence } \\
\text { generation }\end{array}$ & $\begin{array}{c}\text { Allocation } \\
\text { concealment }\end{array}$ & Blind method & $\begin{array}{l}\text { Lost to } \\
\text { follow-up }\end{array}$ & $\begin{array}{l}\text { Intention-to- } \\
\text { treat analysis }\end{array}$ & $\begin{array}{c}\text { Baseline } \\
\text { comparison }\end{array}$ & $\begin{array}{c}\text { Quality } \\
\text { evaluation level }\end{array}$ \\
\hline Lin et al. (9) & Described & Not clear & Single-blind & Described & Not used & Similar data & Level B \\
\hline Tan et al. (11) & Described & Described & Double-blind & Described & Not used & Similar data & Level A \\
\hline Noordzij et al. (12) & Described & Described & Single-blind & Described & Not used & Similar data & Level A \\
\hline Magdy et al. (14) & Described & Described & Double-blind & Described & Not used & Similar data & Level A \\
\hline Chang et al. (15) & Described & Described & Double-blind & Described & Not used & Similar data & Level A \\
\hline Wilson et al. (16) & Described & Described & Double-blind & Described & Not used & Similar data & Level A \\
\hline
\end{tabular}

$\mathrm{P}=0.296)$.

The studies were further divided into 2 subgroups according to the type of patients (adult or pediatric). The results showed that the internal heterogeneity of the pediatric group was $\mathrm{I}^{2}=41.2 \%$ and $\mathrm{P}=0.165$, while the internal heterogeneity of the adult group was $\mathrm{I}^{2}=97.9 \%$ and $\mathrm{P}<0.0001$, as shown in Figure 2.

\section{Intraoperative blood loss}

There were 3 studies $(12,14,15)$ that reported the intraoperative blood loss of the 2 operations (both in $\mathrm{mL}$ ). The effect size was expressed by SMD. The homogeneity test results were $\mathrm{I}^{2}=96.9 \%$ and $\mathrm{P}<0.0001$. Random effects model analysis showed that the intraoperative blood loss using CT was less than that of ET, and the difference was statistically significant (SMD $=-2.62,95 \% \mathrm{CI}:-4.83$ to $-0.41, Z=-2.322, \mathrm{P}=0.020$ ), as shown in Figure 3.

\section{Postoperative pain score}

A total of 7 studies reported the postoperative pain of 


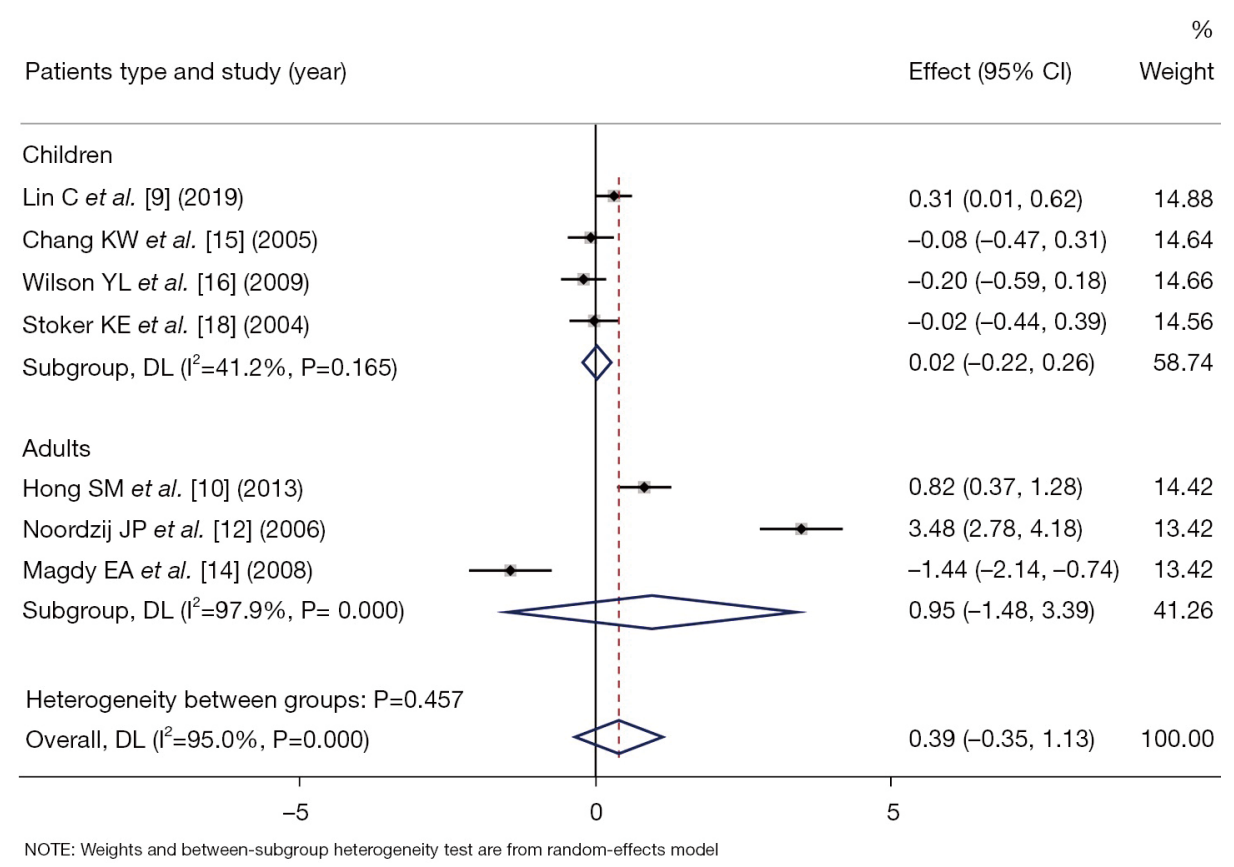

Figure 2 Comparison of operation time between the 2 procedures.

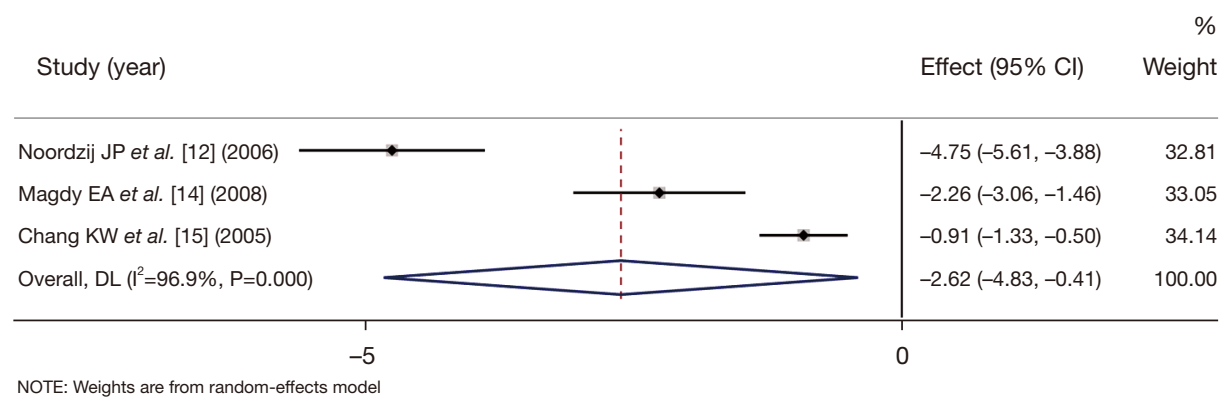

Figure 3 Comparison of intraoperative blood loss between the 2 procedures.

patients following the 2 kinds of surgeries (all studies used the VAS scale). The effect size was expressed by SMD. The homogeneity test results were $\mathrm{I}^{2}=76.9 \%$ and $\mathrm{P}<0.0001$. The random effects model analysis showed that the postoperative pain score of CT was less than that of ET, but the difference was statistically significant $(\mathrm{SMD}=-0.28,95 \% \mathrm{CI}:-0.58$ to $0.01, Z=-1.866$, $\mathrm{P}=0.062)$.

The literature was further divided into 2 subgroups by patient type (adult or pediatric), and the results showed that there was heterogeneity within pediatric patients, as shown in Figure 4.

\section{Time to return to normal diet after surgery}

A total of 6 studies reported the time to return to normal diet (both in days) for the 2 surgeries. The effect size was expressed by SMD. The homogeneity test results were $\mathrm{I}^{2}=55.1 \%$ and $\mathrm{P}=0.049$. The random effects model analysis showed that the time to return to normal diet after CT was less than that after ET, and the difference was statistically significant (SMD $=-0.36,95 \% \mathrm{CI}:-0.60$ to $-0.12, Z=-2.918, \mathrm{P}=0.004)$.

The studies were further divided into 2 subgroups according to the type of patients (adults or pediatric). The results showed that the internal heterogeneity of the 


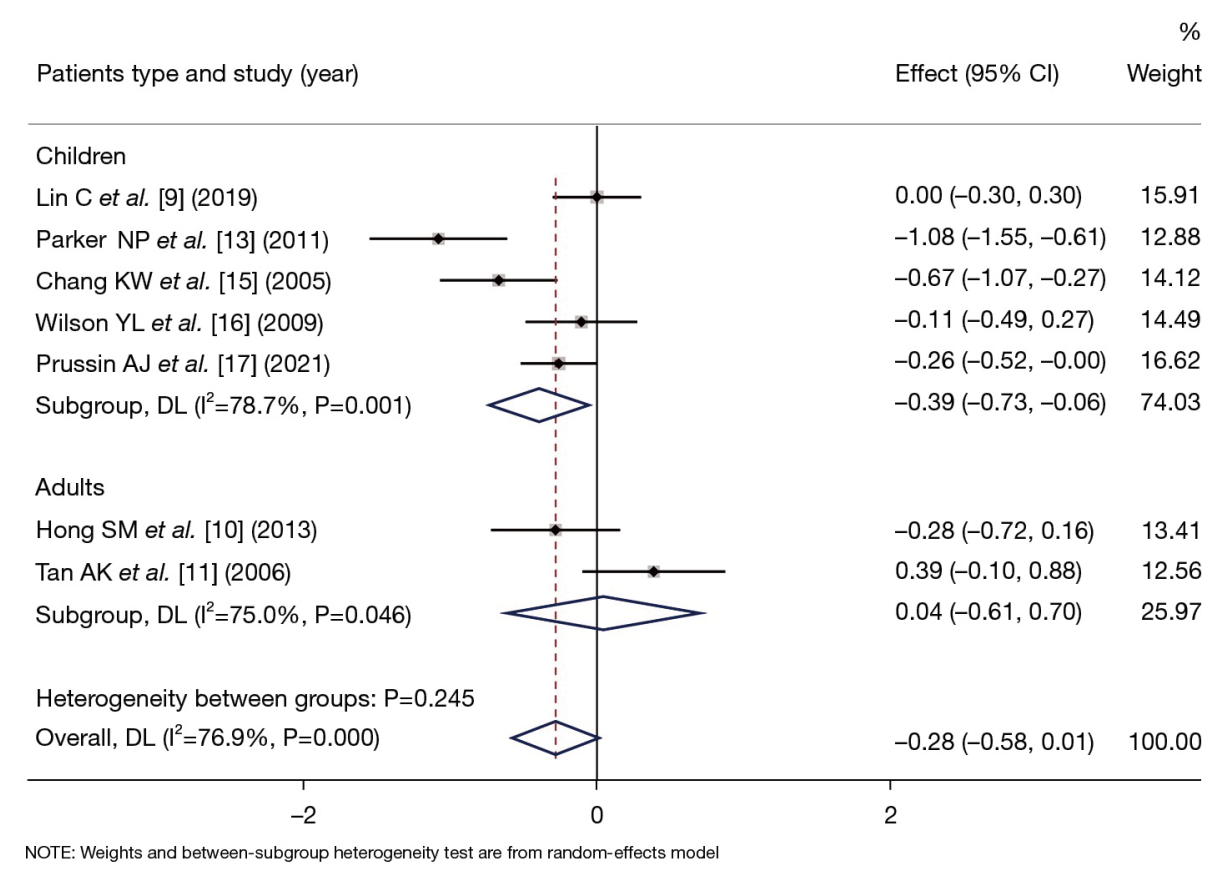

Figure 4 Comparison of Visual Analog Scale scores for intraoperative pain between the 2 procedures.

pediatric group was $\mathrm{I}^{2}=0 \%$ and $\mathrm{P}=0.727$, while the internal heterogeneity of the adult group was $\mathrm{I}^{2}=70.6 \%$ and $\mathrm{P}=0.065$, as shown in Figure 5.

\section{Postoperative complications}

One study (9) reported 2 types of postoperative bleeding, coblation (3\%) and electrocautery $(3.4 \%)$, and there was no significant difference between the 2 groups $(\mathrm{P}>0.05)$. It was reported in another study (17) that there were 6 cases of bleeding, 2 cases of vomiting, 3 cases of dehydration, and a total of 17 cases $(15.2 \%)$ of complications after coblation, while there were 2 cases of bleeding, 3 cases of vomiting, 2 cases of dehydration, and a total of 20 cases $(16.9 \%)$ of complications after electrocautery. There was no significant difference in the incidence rate of total complications between the 2 groups $(\mathrm{P}>0.05)$. No complications were reported in other studies.

\section{Heterogeneity investigation}

In the analysis of operation time and time to return to normal diet after surgery, the study was divided into the pediatric group and adult group. There was no internal heterogeneity in the pediatric group, but there was high heterogeneity in the adult group. Thus, the age of the patients was an important source of heterogeneity. In addition, the disease type of patients (those with tonsillitis, inflammatory patients who had recurrence after the operation, patients with tonsillar hypertrophy) was also a source of heterogeneity.

\section{Sensitivity analysis}

In the sensitivity analysis of operation time, the results of 7 studies had similar distribution on both sides and good stability, as shown in Figure 6.

\section{Analysis of publication bias}

The funnel plot of operation time showed that the distribution of the left and right sides in 7 studies was basically symmetrical, indicating no significant publication bias, as shown in Figure 7.

\section{Discussion}

Tonsillectomy is an important method for the treatment of tonsillitis. Different surgical methods have different operation times and amounts of intraoperative bleeding, which has a great impact on postoperative pain, the control of complications, and therapeutic effects (19). In this study, a total of 10 RCTs on the comparison between CT and ET 


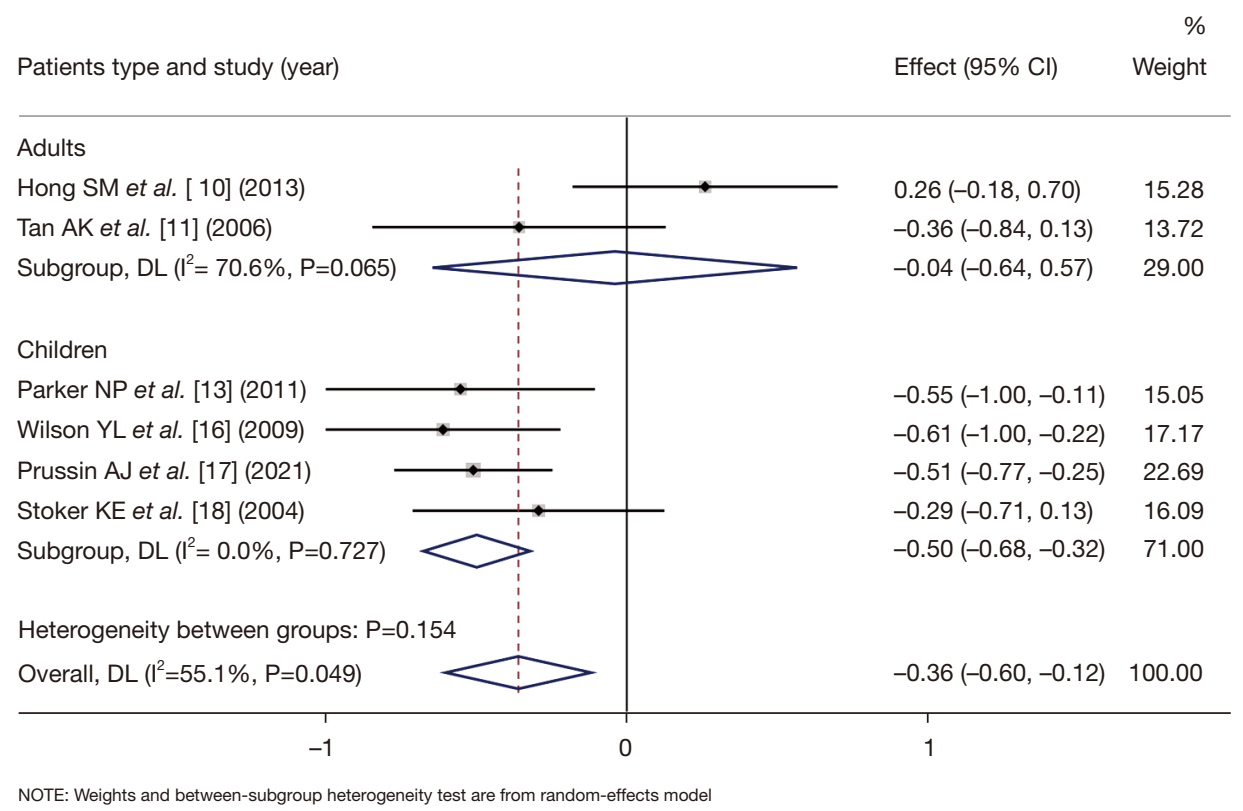

Figure 5 Comparison of time to return to normal diet after surgery between the 2 procedures.

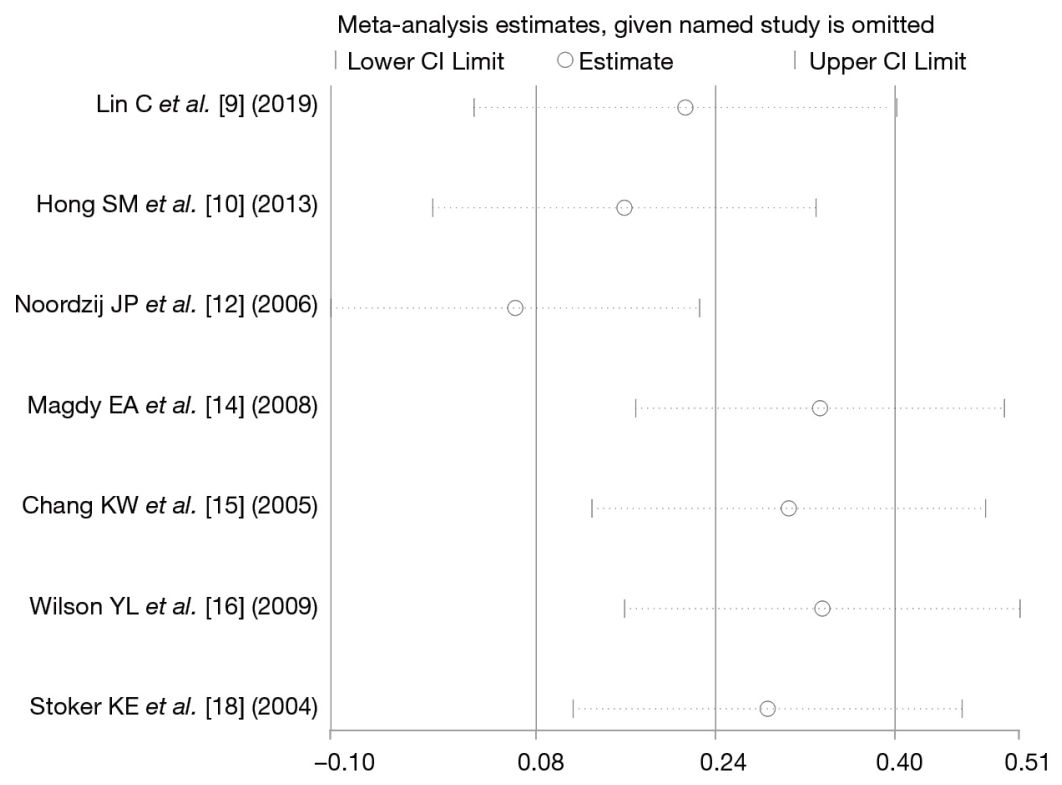

Figure 6 Sensitivity analysis.

were screened. The study results showed that compared with ET, CT could significantly reduce intraoperative blood loss and postoperative rehabilitation time, but there were no significant differences in the operation time, postoperative pain, and the incidence rate of postoperative complications compared with ET.
In this meta-analysis, 3 studies $(9,10,12)$ reported that the time of CT surgery was longer than that of ET, and the pooled effect size showed that the time of CT surgery was longer, but the difference between the 2 was not statistically significant. Some studies (20) concluded that the electrosurgical knife used in ET surgery has a smaller blade, 


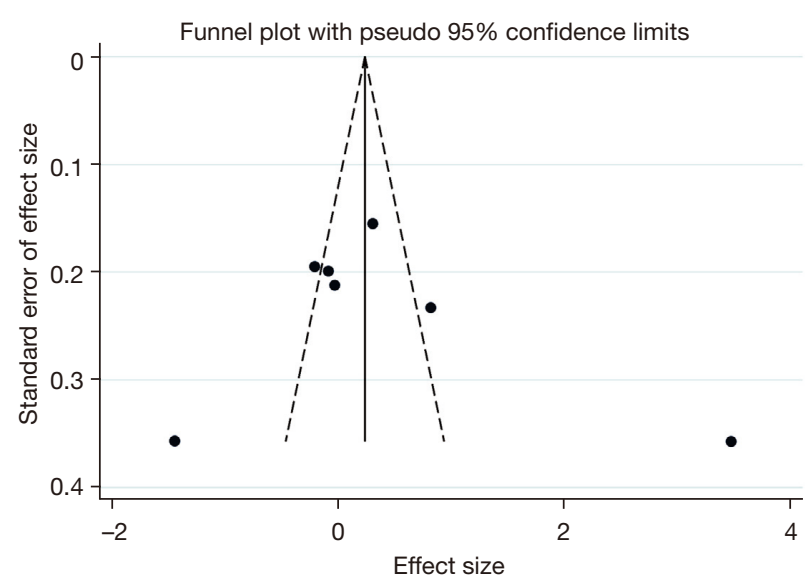

Figure 7 Funnel plot of publication bias.

smaller contact surface, and more precise control of energy and discharge direction than CT. Therefore, the operation is more convenient and quick, and the operation time is shorter. However, more clinical studies are needed to prove this.

In this study, the combined effect size of 3 studies showed that CT surgery resulted in less intraoperative blood loss than ET surgery. The tonsils are rich in blood vessels and can easily bleed during surgery. ET produces a large amount of thermal energy and high temperature. Through this electrothermal effect, the separation and coagulation of body tissues are realized, thus playing a role in cutting and hemostasis. However, during electrocoagulation hemostasis, scabs can easily form, resulting in weakened clarity of the surgical field (21). CT has a suction function. Cutting and hemostasis are completed almost simultaneously using the same blade while cutting. Due to the rapid hemostasis, the anatomical level of the surgical field is very clear, and a proficient operator can even achieve a completely bloodless operation, which significantly reduces the occurrence of intraoperative blood loss (22).

Pain is a common reaction after tonsillectomy. ET can burn the superficial tissue of the wound surface at a high temperature (usually $>400{ }^{\circ} \mathrm{C}$ ) so as to separate the tissue. The burning effect may damage the deep tissue, resulting in local edema and release of inflammatory mediators, thus causing pain (23). Although CT can work at a low temperature $\left(40-70^{\circ} \mathrm{C}\right)$, with less thermal damage and less local edema, it can also cause muscle and mucosal tears (24). Therefore, there was no significant difference in postoperative pain between the 2 procedures.

The time (days) to return to normal diet and activity after surgery is an important efficacy indicator of tonsillectomy. In this study, the results of the combined effect showed that the postoperative recovery of CT surgery was faster than that of ET surgery, which may be related to the fact that CT results in less thermal damage to the surrounding tissues and forms a significant boundary between the coagulative necrosis area caused by radiofrequency ablation and the surrounding tissues. Therefore, the surgical trauma was smaller, the degree of postoperative local edema was mild, and recovery was faster.

The cost of surgery is also a factor to be considered. Some studies (25) compared the 2 costs of CT and ET. The results showed that the cost of ET surgery and intraoperative anesthesia time were significantly higher. However, this study didn't include enough literatures for the analysis of these outcome indicators. These indicators can be analyzed in future studies.

In this study, factors that may significantly cause heterogeneity were excluded. For example, the pain scoring criteria used in each study were not uniform, and the data unit was not uniform with the reporting method. However, the final analysis results still showed that there was significant heterogeneity between the studies. After the study was divided into 2 subgroups of pediatric and adult patients, the heterogeneity disappeared in the pediatric group, indicating that the age of patients is an important source of heterogeneity which is related to differences in the physiological characteristics and tolerance of patients in different age groups. This meta-analysis showed that the application of CT in pediatric patients resulted in a shorter operation time and lower postoperative pain, but this needs to be confirmed by more controlled clinical trials.

All literature included in this study mentioned the random sequence generation method and blind method. Only 2 studies did not describe the allocation concealment. The quality of the literature was high. However, some indicators (such as intraoperative blood loss) were only included in few studies. Large sample size, multi-center, controlled clinical studies are still needed on this topic to provide stronger evidence.

\section{Conclusions}

In summary, CT resulted in less intraoperative blood loss and faster postoperative recovery than ET, but there was no significant difference in operation time, postoperative pain, and the incidence rate of postoperative complications between the 2 groups. 


\section{Acknowledgments}

Funding: None.

\section{Footnote}

Reporting Checklist: The authors have completed the PRISMA reporting checklist. Available at https:// gs.amegroups.com/article/view/10.21037/gs-21-832/rc

Conflicts of Interest: All authors have completed the ICMJE uniform disclosure form (available at https://gs.amegroups. com/article/view/10.21037/gs-21-832/coif). The authors have no conflicts of interest to declare.

Ethical Statement: The authors are accountable for all aspects of the work in ensuring that questions related to the accuracy or integrity of any part of the work are appropriately investigated and resolved.

Open Access Statement: This is an Open Access article distributed in accordance with the Creative Commons Attribution-NonCommercial-NoDerivs 4.0 International License (CC BY-NC-ND 4.0), which permits the noncommercial replication and distribution of the article with the strict proviso that no changes or edits are made and the original work is properly cited (including links to both the formal publication through the relevant DOI and the license). See: https://creativecommons.org/licenses/by-nc-nd/4.0/.

\section{References}

1. Mitchell RB, Archer SM, Ishman SL, et al. Clinical Practice Guideline: Tonsillectomy in Children (Update). Otolaryngol Head Neck Surg 2019;160:S1-S42.

2. Wong Chung JERE, van Benthem PPG, Blom HM. Tonsillotomy versus tonsillectomy in adults suffering from tonsil-related afflictions: a systematic review. Acta Otolaryngol 2018;138:492-501.

3. Cooper CM, Checketts JX, Brame L, et al. An analysis of the literature addressing tonsillectomy knowledge gaps. Int J Pediatr Otorhinolaryngol 2018;115:89-93.

4. Wulu JA, Chua M, Levi JR. Does suturing tonsil pillars post-tonsillectomy reduce postoperative hemorrhage?: A literature review. Int J Pediatr Otorhinolaryngol 2019;117:204-9.

5. Carr MM, Patel VA, Soo JC, et al. Effect of Electrocautery Settings on Particulate Concentrations in Surgical Plume during Tonsillectomy. Otolaryngol Head Neck Surg 2020;162:867-72.

6. Mofatteh MR, Salehi F, Hosseini M, et al. Comparison of postoperative morbidity between conventional cold dissection and bipolar electrocautery tonsillectomy: which technique is better? Braz J Otorhinolaryngol 2020;86:427-33.

7. Pynnonen M, Brinkmeier JV, Thorne MC, et al. Coblation versus other surgical techniques for tonsillectomy. Cochrane Database Syst Rev 2017;8:CD004619.

8. Lee YC, Hsin LJ, Lin WN, et al. Adolescents and Adults Undergoing Temperature-Controlled Surgical Instruments vs Electrocautery in Tonsillectomy: A Systematic Review and Meta-analysis of Randomized Clinical Trials. JAMA Otolaryngol Head Neck Surg 2020;146:339-46.

9. Lin C, Thung AK, Jatana KR, et al. Impact of coblation versus electrocautery on acute post-operative outcomes in pediatric tonsillectomy. Laryngoscope Investig Otolaryngol 2018;4:154-9.

10. Hong SM, Cho JG, Chae SW, et al. Coblation vs. Electrocautery Tonsillectomy: A Prospective Randomized Study Comparing Clinical Outcomes in Adolescents and Adults. Clin Exp Otorhinolaryngol 2013;6:90-3.

11. Tan AK, Hsu PP, Eng SP, et al. Coblation vs electrocautery tonsillectomy: postoperative recovery in adults. Otolaryngol Head Neck Surg 2006;135:699-703.

12. Noordzij JP, Affleck BD. Coblation versus unipolar electrocautery tonsillectomy: a prospective, randomized, single-blind study in adult patients. Laryngoscope 2006;116:1303-9.

13. Parker NP, Walner DL. Post-operative pain following coblation or monopolar electrocautery tonsillectomy in children: a prospective, single-blinded, randomised comparison. Clin Otolaryngol 2011;36:468-74.

14. Magdy EA, Elwany S, el-Daly AS, et al. Coblation tonsillectomy: a prospective, double-blind, randomised, clinical and histopathological comparison with dissection-ligation, monopolar electrocautery and laser tonsillectomies. J Laryngol Otol 2008;122:282-90.

15. Chang KW. Randomized controlled trial of Coblation versus electrocautery tonsillectomy. Otolaryngol Head Neck Surg 2005;132:273-80.

16. Wilson YL, Merer DM, Moscatello AL. Comparison of three common tonsillectomy techniques: a prospective randomized, double-blinded clinical study. Laryngoscope 2009;119:162-70.

17. Prussin AJ, Babajanian E, Error M, et al. Radiofrequency Ablation vs Electrocautery Blinded Randomized Trial: 
Impact on Clinically Meaningful Outcomes. Otolaryngol Head Neck Surg 2021;164:1186-92.

18. Stoker KE, Don DM, Kang DR, et al. Pediatric total tonsillectomy using coblation compared to conventional electrosurgery: a prospective, controlled single-blind study. Otolaryngol Head Neck Surg 2004;130:666-75.

19. Grobler A, Carney AS. Radiofrequency coblation tonsillectomy. Br J Hosp Med (Lond) 2006;67:309-12.

20. Sproat R, Radford P, Hunt A. Hemostatic glues in tonsillectomy: A systematic review. Laryngoscope 2016;126:236-42.

21. Du W, Ma B, Guo Y, et al. Microdebrider vs. electrocautery for tonsillectomy: a meta-analysis. Int J Pediatr Otorhinolaryngol 2010;74:1379-83.

22. Zhou X, Xu A, Zhen X, et al. Coblation tonsillectomy

Cite this article as: Cai FG, Hong W, Ye Y, Liu YS. Comparative systematic review and meta-analysis of the therapeutic effects of coblation tonsillectomy versus electrocautery tonsillectomy. Gland Surg 2022;11(1):175-185. doi: $10.21037 / g s-21-832$ versus coblation tonsillectomy with ties in adults. J Int Med Res 2019;47:4734-42.

23. Metcalfe C, Muzaffar J, Daultrey C, et al. Coblation tonsillectomy: a systematic review and descriptive analysis. Eur Arch Otorhinolaryngol 2017;274:2637-47.

24. Lieberg N, Aunapuu M, Arend A. Coblation tonsillectomy versus cold steel dissection tonsillectomy: a morphological study. J Laryngol Otol 2019;133:770-4.

25. McCoy JL, Maguire RC, Tobey ABJ. Cost benefit of coblation versus electrocautery adenotonsillectomy for pediatric patients. Int J Pediatr Otorhinolaryngol 2020;136:110197.

(English Language Editor: C. Betlazar-Maseh) 